\title{
Urban Feature Extraction from Merged Airborne LiDAR Data and Digital Camera Data
}

\author{
L. G. E. Taha ${ }^{a^{*}}$ (iD , A. I. Ramzi , A. Sharawi ${ }^{\text {a }}$ (D) , A. Bekheet ${ }^{\mathrm{a}}$ \\ ${ }^{a}$ Aviation and Aerial photography division, National Authority of Remote Sensing and Space Science (NARSS), Egypt
}

\section{Article Info:}

Received: 25 November 2019 in revised form: January 2020 Accepted: March 2020 Available Online: 1 November 2020

\section{Keywords:}

LIDAR, Digital photogrammetric camera, True orthoimage, Digital photogrammetry, Matching, DSM, Texture

\section{*Corresponding Author:}

L. G. E. Taha

Aviation and Aerial photography division, National Authority of Remote Sensing and Space Science (NARSS), Egypt

Email: Lamyaa@narss.sci.eg

How to cite (APA 6th Style):

Taha, L., Ramzi, A., Syarawi, A., \& Bekheet, A. (2020). Urban Feature Extraction from Merged Airborne LiDAR Data and Digital Camera Data. Geoplanning: Journal of Geomatics and Planning, 7(2), 57-74. doi: 10.14710/geoplanning.7.2.57-74

\begin{abstract}
Until recently, the most highly accurate digital surface models were obtained from airborne lidar. With the development of a new generation of large format digital photogrammetric aerial cameras, a fully digital photogrammetric workflow became possible. This research concerned with the generation of digital surface models and orthophotos as applications from high-resolution images. True digital ortho from the digital aerial camera and orthoimage will be generated using the LIDAR digital elevation model. Leica Photogrammetric Suite (LPS) module of Erdas Imagine 2014 software was utilized for processing. The results show that the automatic digital surface model DSM produced from the digital aerial camera method has very high dense photogrammetric $3 D$ point clouds compared to the LIDAR 3D point clouds. The best cue integration is intensity (pan) $+n D S M+e n t r o p y$ followed by intensity (pan) $+n D S M+m e a n$ then intensity image+mean+entropy after that DSM) image and two texture measures (mean and entropy) followed by the color image. The maximum likelihood classifier is the best followed by minimum distance and the neural network classifier.
\end{abstract}

Copyright (C) 2020 GJGP-UNDIP This open access article is distributed under a This open access article is distributed under
Creative Commons Attribution (CC-BY-NC-SA) 4.0 International license.

\section{INTRODUCTION}

LIDAR is a mature remote sensing technology that can provide accurate elevation data for topographic surfaces and above-ground objects (Yunfei et al., 2008). LIDAR consists of three main components: (i) (GNSS), (ii) an Inertial Measurement Unit (IMU), and (iii) a Laser Scanner Unit. While the GNSS receiver is used to record the aircraft position, the IMU measures the angular attitude of the aircraft (roll, pitch, and yaw or heading). The Laser Scanner Unit transmits pulses of light toward the surface of interest and records both the travel time of the laser beam and the energy, which is reflected by the surface (Jochem et al., 2009). A LiDAR sensor delivers 3D point clouds with the intensities of the returned signals. A point cloud is a collection of discrete three-dimensional locations (points) that can have additional metadata associated with each record. LiDAR has become a valuable data source for urban feature acquisition (buildings and roads). Buildings and roads data are important for urban planning.

The potential of digital photogrammetry was already demonstrated for different applications and datasets, including aerial images, satellite images, or video sequences (Haala \& Rothermel, 2012). Photogrammetric imaging methods are being converted from analog to digital (Honkavaara et al., 2008). Digital photogrammetric cameras of large-format have been commercially introduced since 2000 (L. Zhang et al., 2006). High resolution and high spectral digital cameras improved image quality. This means new potential for automatic image measurement and interpretation. Digital imaging, coupled with advanced direct georeferencing methods, makes updated georeferenced imagery available for users within hours of image collection (Honkavaara et al., 2008).

The digital photogrammetry era has also enabled new methods for elevation (DSM) extraction using automatic image matching technique (Demir, Poli, \& Baltsavias, 2008). It has also enabled new methods of 
image processing to be used in orthophoto production. Until recently, the collection of high-quality digital surface models was assigned to airborne lidar use. The increasing quality of digital airborne cameras and improvements in matching algorithms allow for an automatic image-based acquisition as a suitable alternative (Haala \& Rothermel, 2012). Matching algorithms, autonomous orientation of images by means of automatic aerial triangulation ease the use of photogrammetry and reduce the costs in digital maps production (Rinaudo et al., 2010).

A classifier is an algorithm that takes a set of parameters (or features) that characterize objects (or instances) and uses them to determine the type (or class) of each object (Mandal \& Prabaharan, 2006). The most common approach to the segmentation and interpretation of multi-spectral remotely sensed data for land cover mapping utilizes a suite of probabilistic classification and clustering algorithms. Supervised classifications may be considered to comprise three distinct stages: training, allocation, and testing (Foody \& Mathur, 2004). Supervised classifications exploit the radiometric properties of known 'training' regions to identify areas elsewhere on the image with similar spectral properties. The hypothesis is that the land cover of the training regions is identical to regions elsewhere in the scene with similar spectral characteristics (Wyatt, 2000). It is important and difficult to select training data that are truly representative of spectrally unique classes (Wyatt, 2000). In this work, five classifiers have been performed. Maximum likelihood (MLC), minimum distance (MD), Support vector machine (SVM), artificial neural network (ANN), and spectral angler

In this research, the automatic digital surface model DSM was produced from a digital aerial camera and from LIDAR data. True digital ortho has been generated from a digital aerial camera also orthoimage will be generated using LIDAR digital elevation model (DSM). This research method will be proposed for feature extraction based on subpixel based (neural network) and pixel-based (minimum distance and maximum likelihood).

\section{DATA AND METHODS}

\subsection{Study Area and Data}

Free sample dataset of downtown Toronto / Canada, North America, kindly provided by the (ISPRS) summer 2017. The aerial images were captured by the Microsoft Vexcel's UltraCam-D (UCD) camera, and the LiDAR data were captured with Optech airborne laser scanner ALTMORION M. The area contains high-rise buildings.

Digital Aerial Images taken by UltraCam-D cover the downtown of Toronto which was operated and processed by FBS (First Base Solutions) company located in the Greater Toronto Area in Canada. The data consist of strip 3 with $60 \%$ forward overlap. The images were taken from an altitude of $1600 \mathrm{~m}$ above ground. The total number of the images in the test area is 3 and the exterior orientation parameters are provided. The image size is $7500 \times 11500$ pixels and the pixel size is $9 \mu \mathrm{m}$, the interior and exterior orientation parameters of the images are available. See Table 2 and Table 3. The "Downtown Toronto" datasets also provide ALS data acquired by Optech. Optech flew over the "Downtown Toronto" area and acquired ALS data using Optech's ALTM-ORION M in February 2009 with the aircraft speed of 120 knots at the flying altitude of $650 \mathrm{~m}$. The ALTM ORION M operates at a wavelength of $1064 \mathrm{~nm}$ (Near Infrared) and scans the underlying topography with a scan width of 20 degrees and the scan frequency of $50 \mathrm{~Hz}$. The reflected echoes were digitized at a sampling rate of $100 \mathrm{kHz}$.

The data set consists of 6 strips and point density is approximately 6.0 points $/ \mathrm{m} 2$. The ALS data provided is formatted in ASPRS's LAS 1.3 format and refers to the same coordinate system as the orientation parameters of the UltraCam-D images. In addition to the original ALS point cloud, a digital surface model (DSM) is provided.

\subsection{Methodology}

The methods of this study are:

1. Aerial image orientation, triangulation.

2. Generation of Digital Surface Model (DSM) from the digital aerial camera using LPS module in Erdas Imagine and generation of DSM using Lastools. 
3. Generation of RGB Orthoimage from both DSM produced from the digital aerial camera and LIDAR DSM.

4. Multi cue extraction will be performed.

- Extraction of two texture measures (mean, entropy)

- Generation of intensity image using Lastools.

- Generation of the fused image from(Pan intensity image, texture, and RGB Orthoimage from LIDAR DSM).

5. Classification of the orthorectified image based on LIDAR DSM using subpixel based (neural network ) and pixel based ( minimum distance and maximum likelihood).

6. Classification of layers stacked images(multi cue integrated) was performed

- In the first approach, the aerial color image was fed into the classifiers.

- In the second approach, combined height information from LIDAR data (DSM )image and two texture measures (mean and entropy) were fed into the classifiers.

- In the third approach, combined intensity image and two texture measures (mean and entropy) were fed into the classifiers.

- In the fourth approach, combined intensity image and nDSM and mean texture measures were fed into the classifiers.

- In the fifth approach, intensity image and nDSM and entropy texture measures were fed into the classifiers.

- Assessment of Classification accuracy.

\subsubsection{Photogrammetric project creation}

Photogrammetric project creation means defining a project name, the reference coordinate system, datum, units, and the used camera for the project. A project was created to include digital camera images. Leica Photogrammetric Suite (LPS) module of Erdsa Imagine 2014 software was utilized for processing. Figure 1 shows Strip 2 configuration.

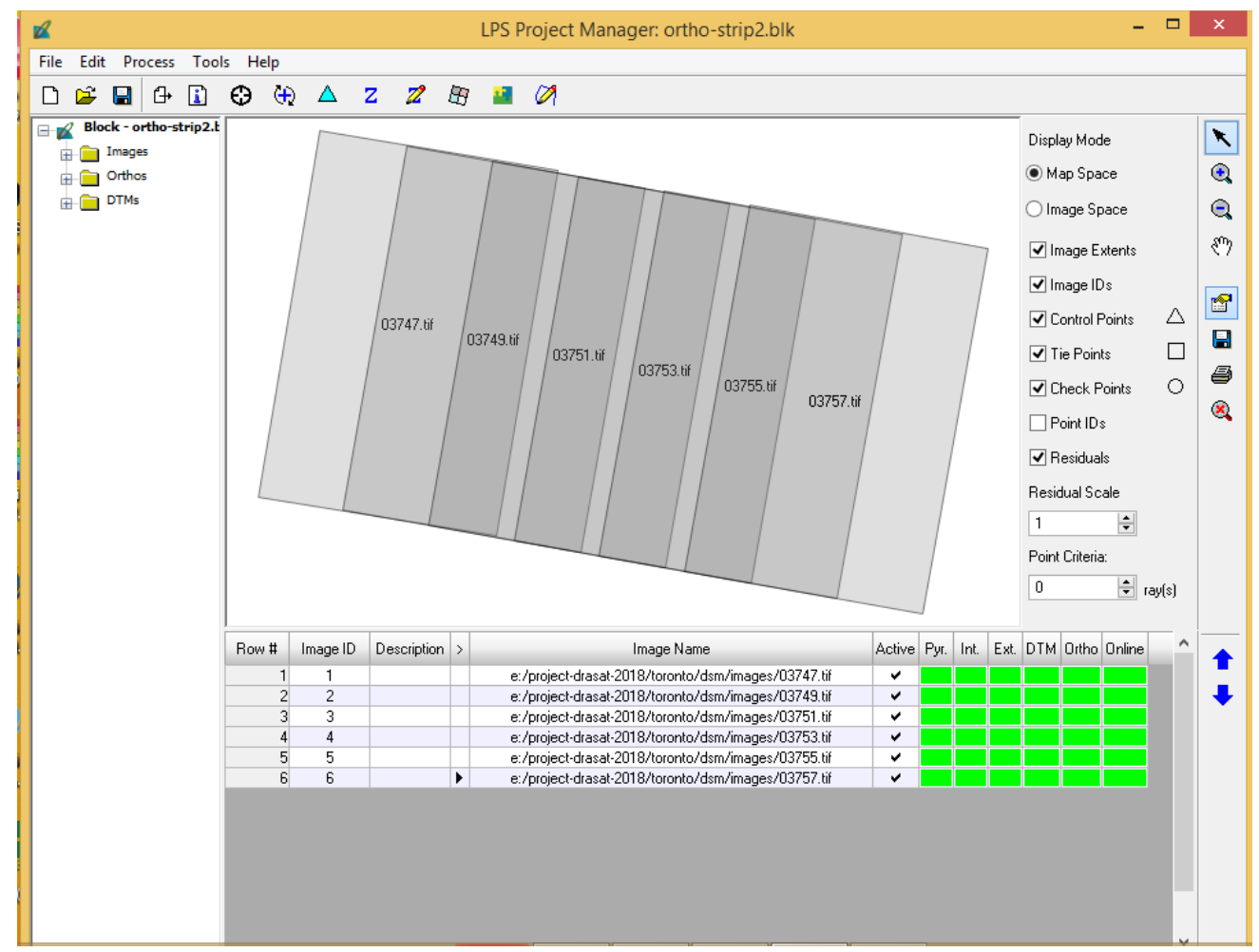

Figure 1. Strip 2 configuration (digital sensor camera) 


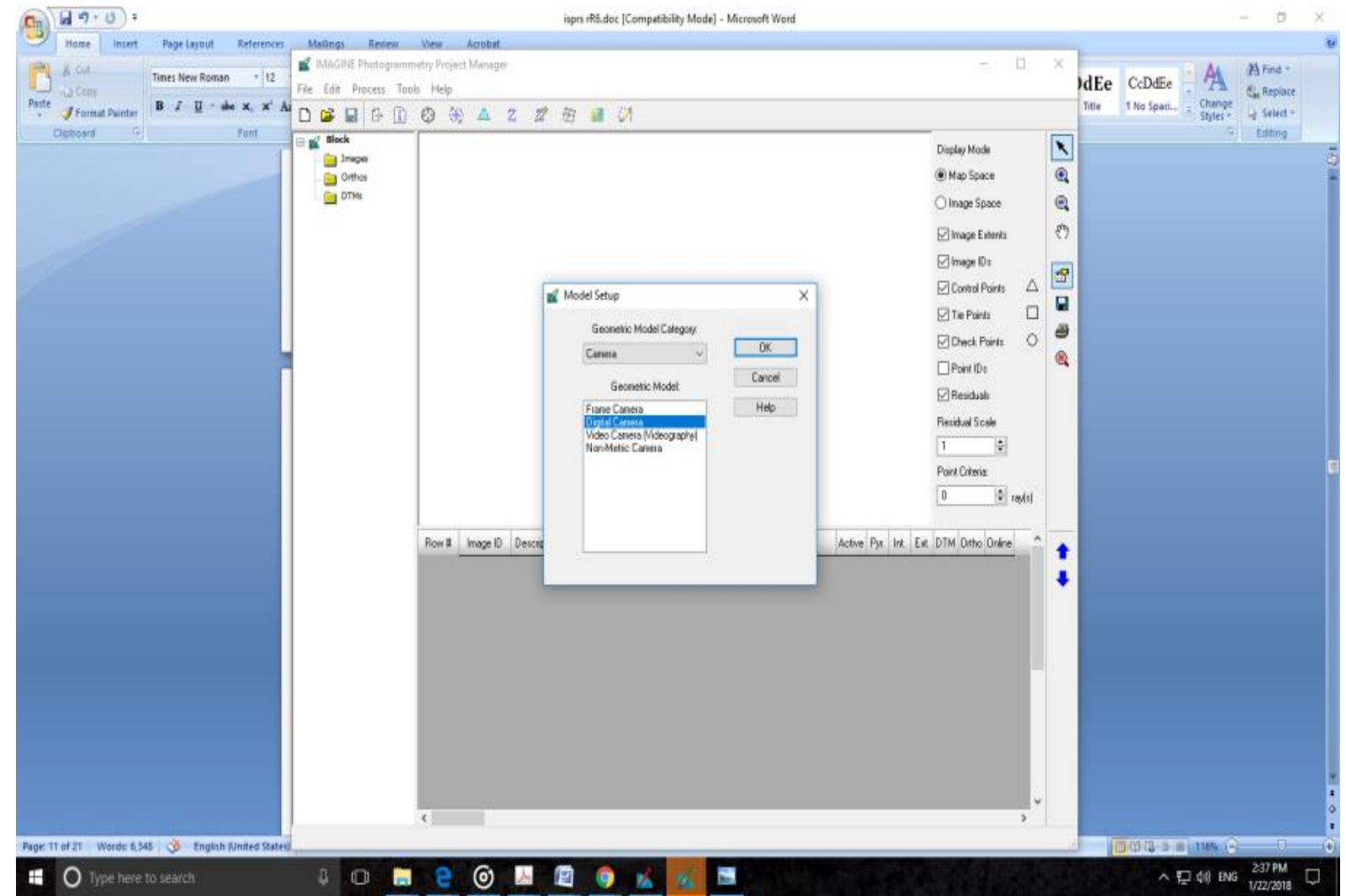

Q IMAGINE Photogrammetry Project Manager: t2018.bl

File Edit Process Tools Hel

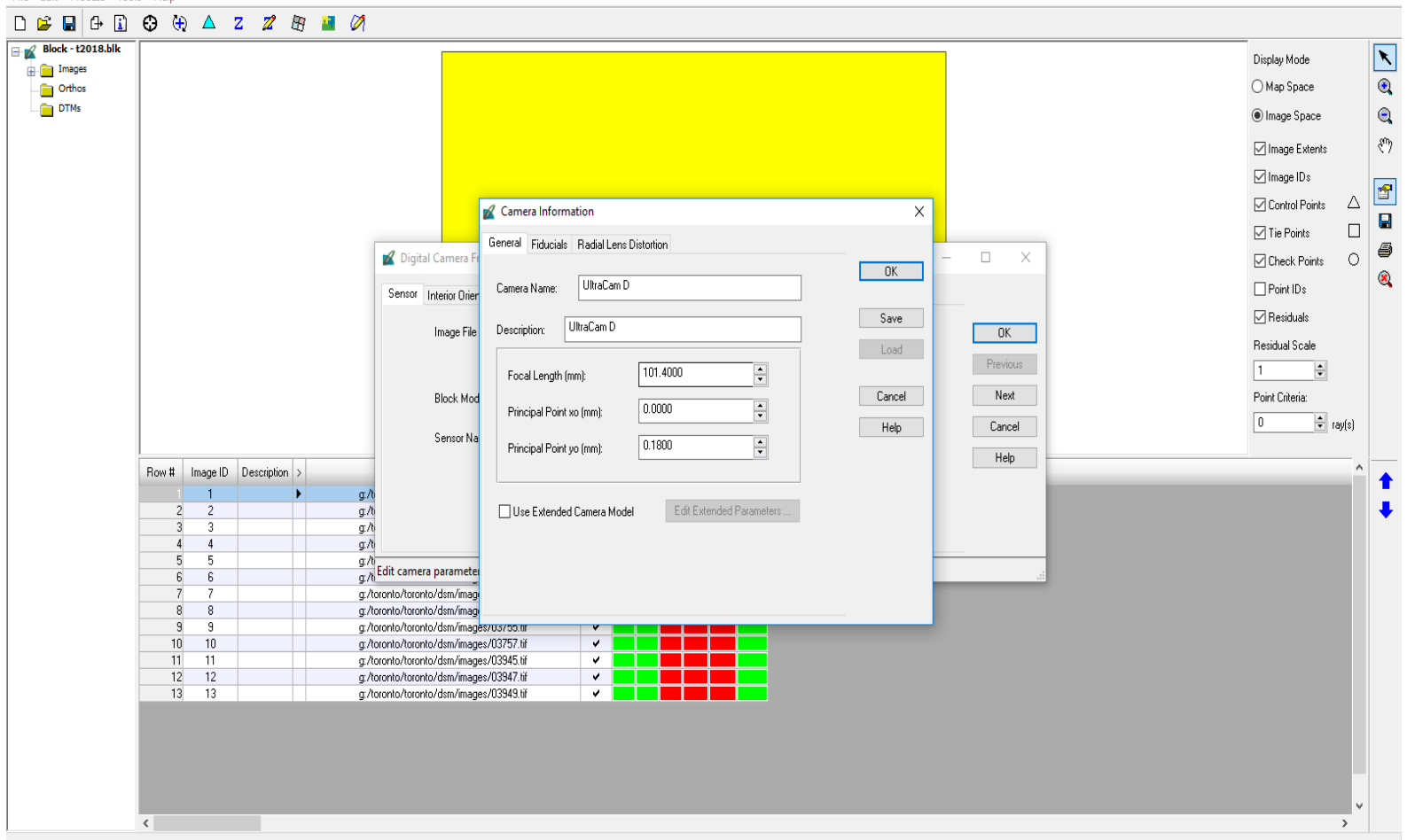

Figure 2. Sensor definition 


\subsubsection{Importing images}

Importing images is the most sophisticated data conversion process because it usually involves a file with relatively large size. The technique to being used to import data depends on the type of sensor that is associated with the imagery. Erdas Imagine 2014 was used for importing imagery. The following images were imported.

Table 1. Summary of the configuration of the digital aerial camera

Strip2
03747*, 03749*, 03751,
03753, 03755, 03757*

\subsubsection{Computation of image pyramids}

Pyramid layers are used to optimize image display and automatic tie point collection. Using this pyramid, image contents are preserved, and computation times are reduced. Pyramid layers for the images in the strip were computed.

\subsubsection{Image Orientation}

Interior orientation parameters and exterior orientation parameters were defined. The interior orientation parameters were defined for all 6 images according to Table 2.

1. Interior orientation of the digital images.

Table 2. The interior orientation of the digital images of the strip3.

2. Exterior orientation

The exterior orientation parameters were defined for all 13 images according to Figure 3. Aerial triangulation is the process of establishing a mathematical relationship between the images contained in a project, the camera or sensor model, and the ground. The information resulting from aerial triangulation is required as input for the orthorectification, DEM creation, and stereo pair creation processes (Leica, 2006). Leica Photogrammetric Suite (LPS) module of Erdas Imagine 2014 software was utilized for defining exterior orientation parameters.

Table 2. Summary of the configuration of the digital aerial camera

\begin{tabular}{|c|c|c|c|c|c|c|c|}
\hline \multirow[t]{2}{*}{ Strip } & \multirow[t]{2}{*}{ Image file } & \multicolumn{3}{|c|}{ Projection Centres } & \multicolumn{3}{|c|}{$\begin{array}{r}\text { Rotation Angles ( } \omega \text { : primary, } x \\
\Phi: \text { secondary, } y ; \text { : tertiary, z) }\end{array}$} \\
\hline & & $\mathrm{XO}[\mathrm{m}]$ & YO [m] & $\mathrm{ZO}[\mathrm{m}]$ & & & \\
\hline 2 & 03747.tif & 629623.149 & 4834071.793 & 1634.685 & 0.04670 & 0.15983 & -99.55331 \\
\hline 2 & 03749.tif & 630013.209 & 4834069.204 & 1632.655 & 0.06512 & 0.14967 & -100.09653 \\
\hline 2 & 03751.tif & 630403.456 & 4834066.892 & 1631.609 & 0.05856 & 0.14668 & -100.12411 \\
\hline 2 & 03753.tif & 630793.356 & 4834065.998 & 1632.673 & 0.04750 & 0.14308 & -100.16600 \\
\hline 2 & 03755.tif & 631183.635 & 4834064.731 & 1636.076 & 0.04186 & 0.14102 & -100.34950 \\
\hline 2 & 03757.tif & 631572.979 & 4834064.233 & 1639.348 & 0.07123 & 0.12940 & -100.21586 \\
\hline
\end{tabular}




\subsubsection{Automatic tie points generation}

Tie points were generated manually in the overlap area. The resulted RMS of triangulation was $0.192 \mathrm{~m}$.

\section{Triangulation |teration Convergence: Yes Total Image Urit'Weight FMSE:

Figure 3. Aerial Triangulation results

\subsubsection{Digital Surface Model (DSM)}

Digital Surface Model (DSM) includes any buildings, vehicles, vegetation (canopy and understory), as well as the "bare ground". To generate the required 'bare-earth DEM, ground, and non-ground features/data points must be distinguished from each other so that the latter can be eliminated before DEM building (Kunapo, 2005). Figure 4 shows Lidar DSM of the study area. Figure 5 illustrates the resulted digital aerial camera DSM of the study area.

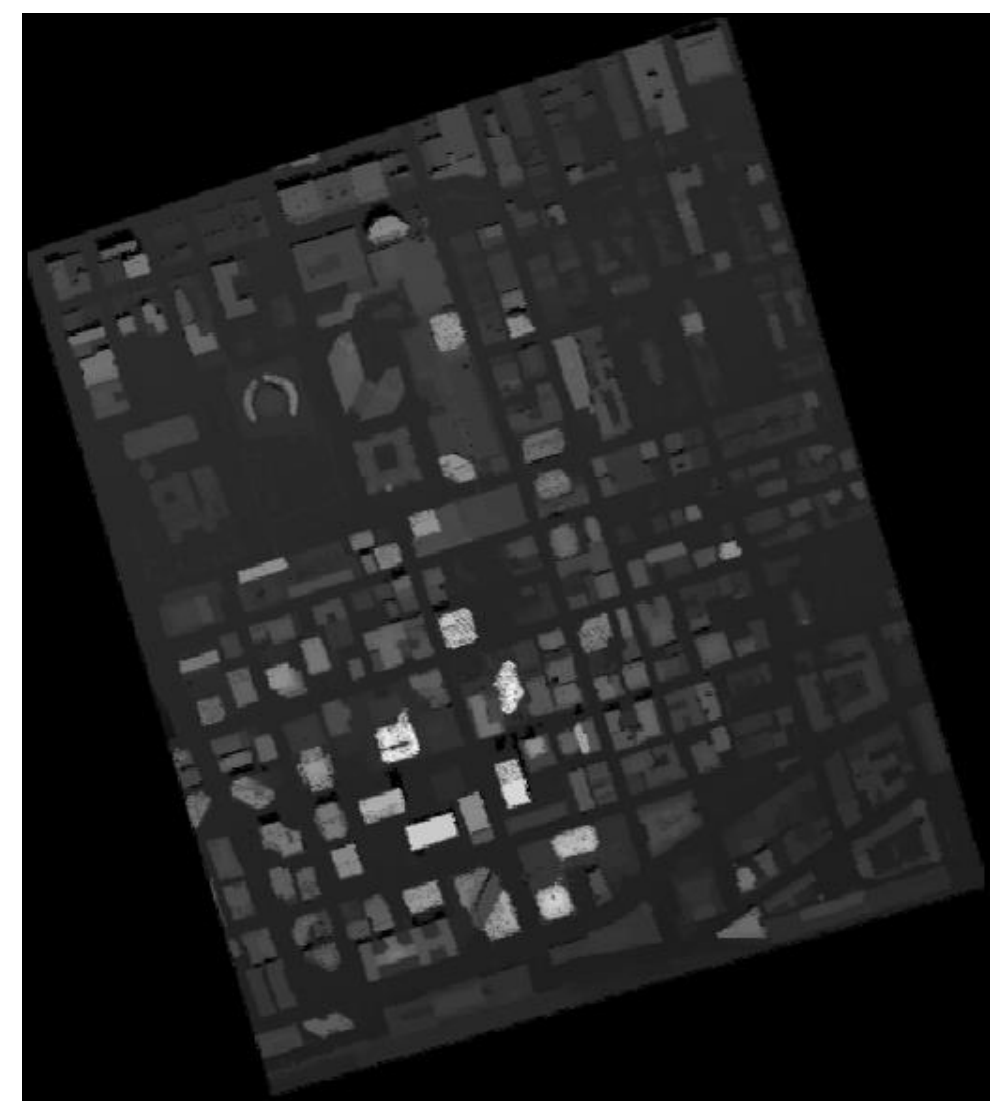

Figure 4. Lidar DSM of the study area 


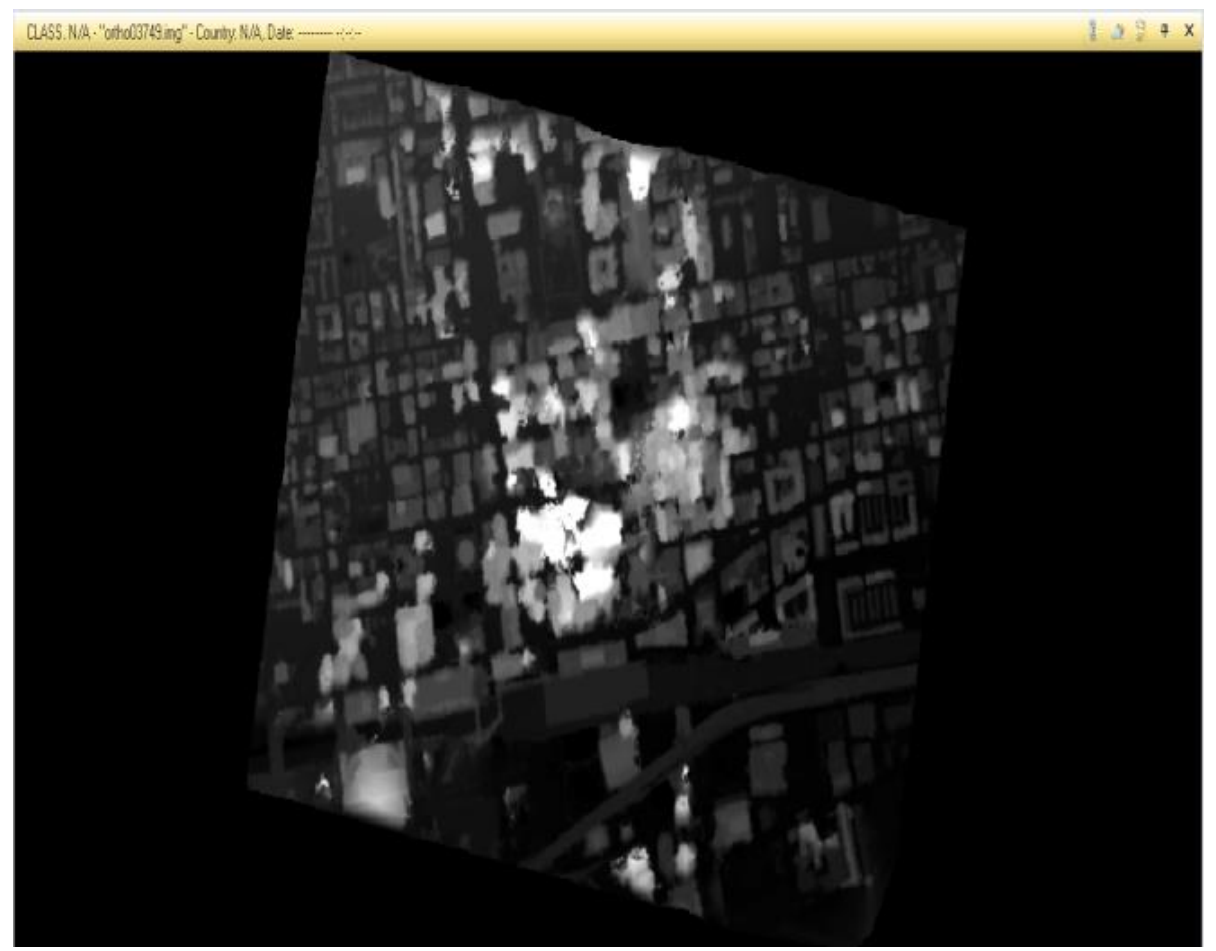

Figure 5. The resulted digital aerial camera DSM of the study area

\subsubsection{Validation using Checkpoints produced using tie-point}

Checkpoints extracted from automatic tie point generation were used for checking the height of LIDAR DSM and digital aerial camera DSM.

$R \hat{M S E}=\sqrt{\frac{1}{n} \sum_{i=1}^{n} \Delta h_{i}^{2}}$

It was found that LIDAR DSM is more accurate than the digital aerial camera DSM. The RMS of LIDAR DSM is $14 \mathrm{~cm}$, while the RMS digital aerial camera DSM is $20 \mathrm{~cm}$.

\subsubsection{True orthoimage generation from a digital photogrammetric aerial camera}

Digital aerial photographs acquired on-flight with a matricial sensor present a pronounced perspective caused by their broad field-of-view (FOV). To change the perspective into orthogonal projection and formulate the topographic correction, internal and external image orientations (IO and EO) and a DEM are required (Valbuena et al., 2011).

The orthoimage generation process consists of five steps: interior orientation, exterior orientation, DEM generation, and editing or using of existing DEM, orthoimages generation, and mosaic creation (Sebari, Lahmami, \& Ettarid, 2011).

Digital aerial photographs were orthorectified to a $15 \mathrm{~cm}$ spatial resolution using Lidar DSM, and digital aerial camera DSM and compared though they were resampled with the nearest neighbor resampling. After that image mosaicking were made. The whole procedure was implemented in Leica photogrammetric suite LPS digital photogrammetric -ERDAS Imagine software 2014. Figure 6.a. depicts an example of true ortho produced using LIDAR DSM Figure 6.b. illustrates a mosaic of digital orthophoto resulting from a digital photogrammetric camera using Lidar DSM. Figure 7 depicts the Overlay of the mosaic of true orthophoto and the digital aerial camera DSM of the study area using swipe utilities. 


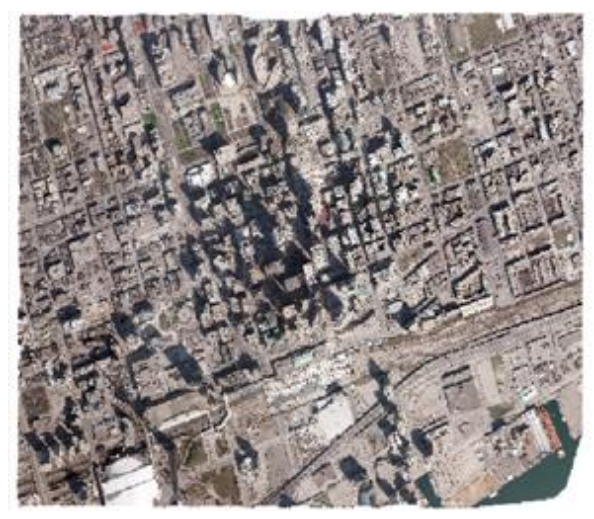

(a)

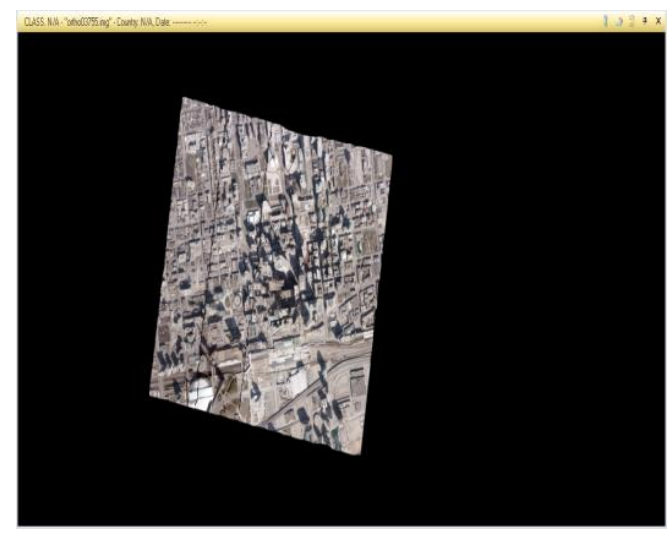

(b)

Figure 6. (a) Example of true ortho of produced using LIDAR DSM and (b) Mosaic of true orthophoto

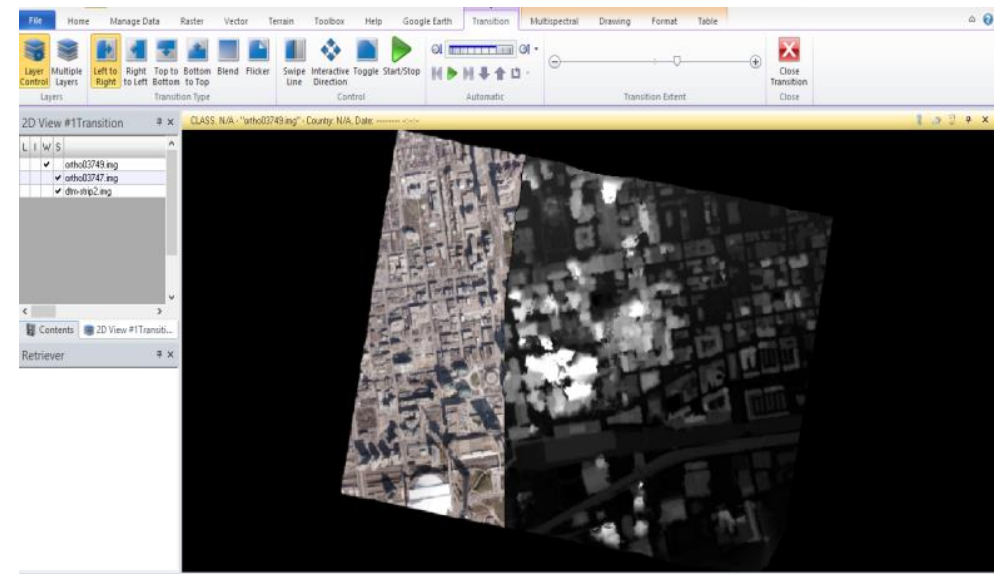

Figure 7. Overlay of the mosaic of true orthophoto and the digital aerial camera DSM of the study area using swipe utilities

\subsubsection{Merging las point clouds}

The merged file of las point cloud was extracted by merging the 6 strips of las point clouds. The lastool software was used for this purpose. Figure 8 depicts merging different las point clouds strips into one file using lastools.

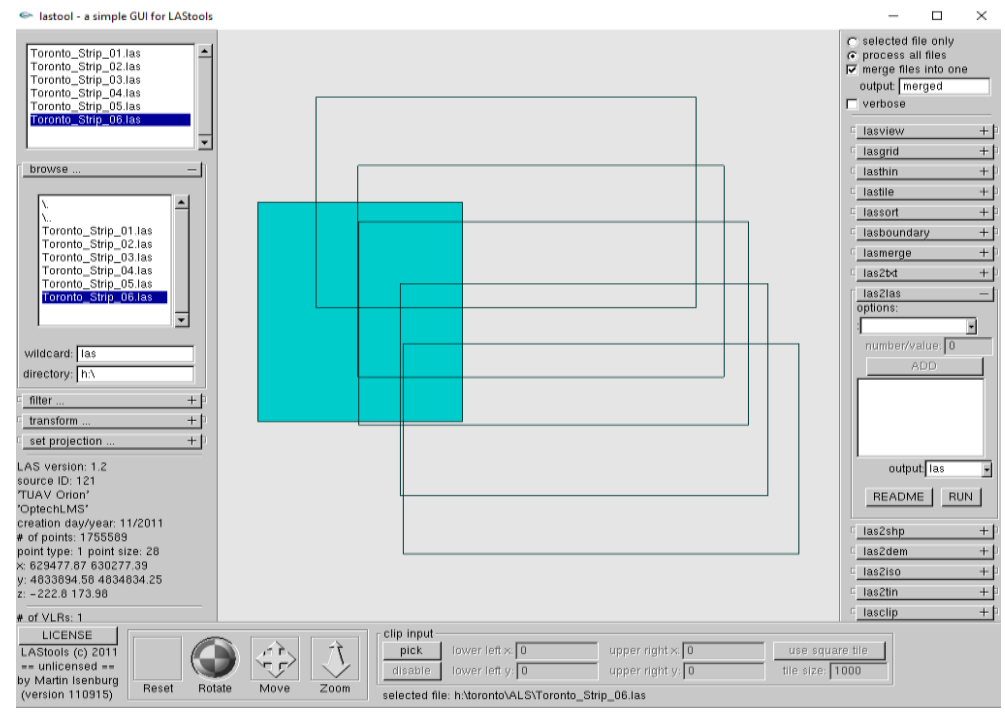

Figure 8. Merging different las point clouds strips into one file using lastools 


\subsubsection{Multi cue extraction}

1. Intensity extraction

Intensity image was extracted from the merged file of the las point cloud using lastool software (Figure 9). The following parameters were used in Lastool software for producing intensity image:

Grid size 3

Item intensity

Output .img

By classification of return: First only

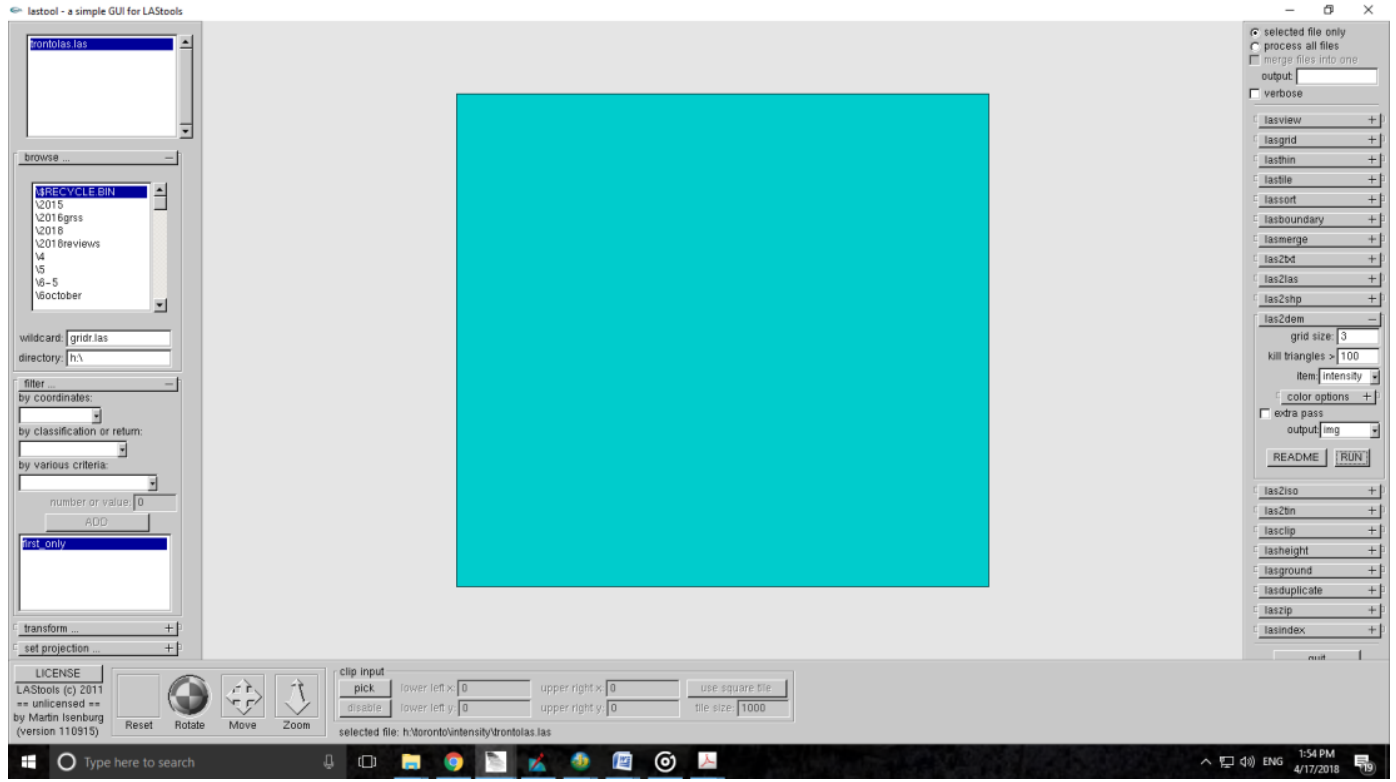

(a)

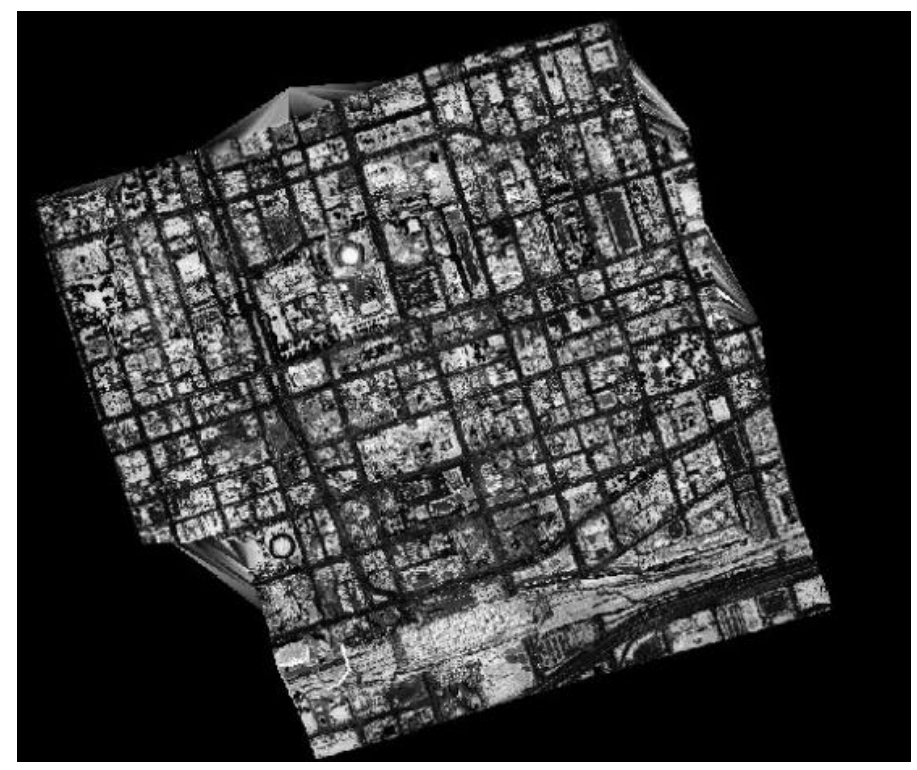

(b)

Figure 9. illustrates extraction using lastools and (b) depicts produced Intensity image from Lastool 


\section{Digital Surface Model (DSM)}

Digital Surface Model (DSM) was produced from the merged file of the las point cloud using lastool software. This is reflected from the surface of objects such as the soil, buildings, cars, leaves, and so on. The process aims to create a high-resolution DSM interpolated from LiDAR data into a regular grid of $3 * 3 \mathrm{~m}$ cells. Lastool was used for producing the DSM (Figure 10). The following parameters were used in Lastool software for producing DSM:

\section{Grid size 3}

Item elevation

Output .img

By classification of return: First only

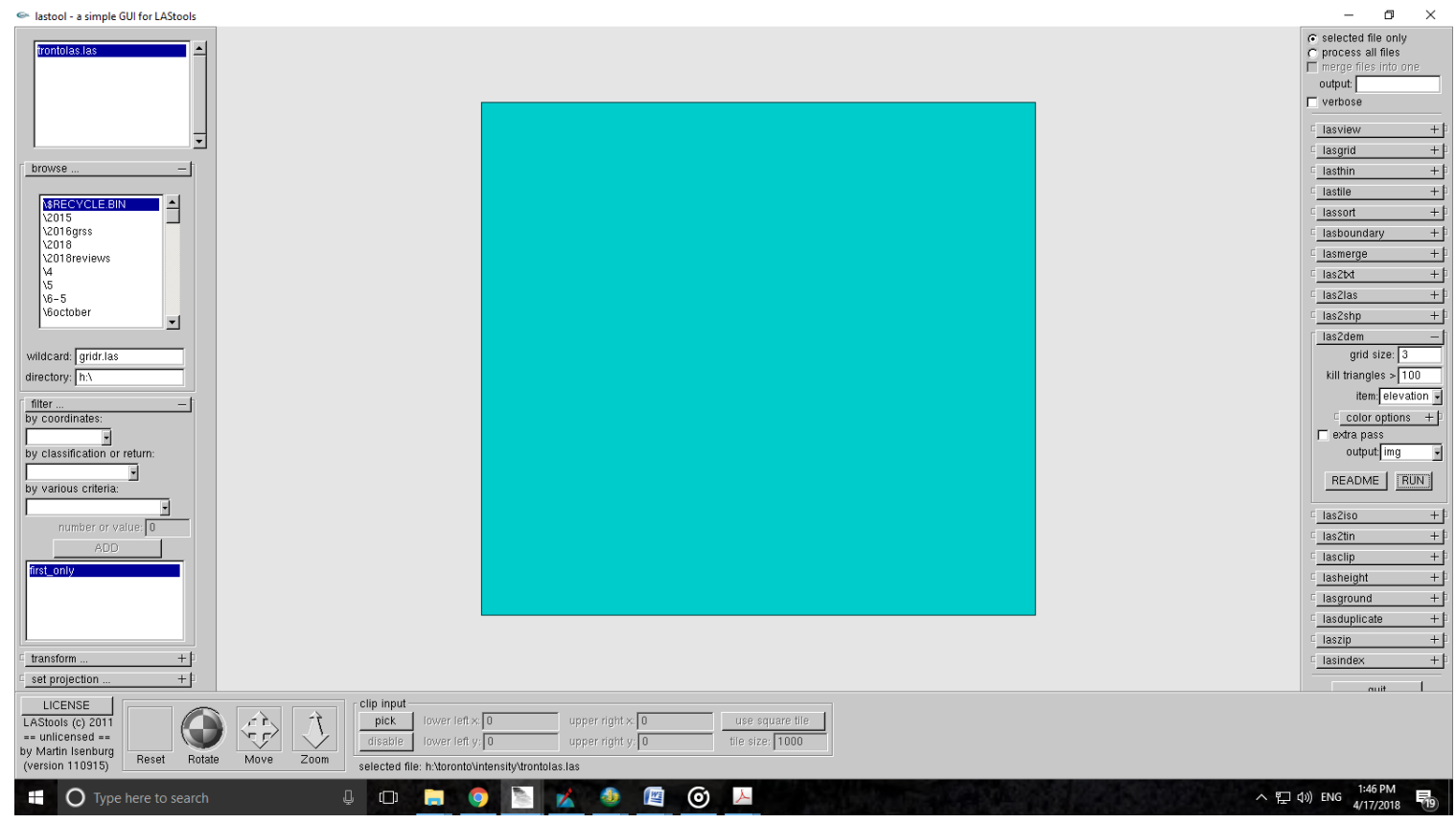

(a)

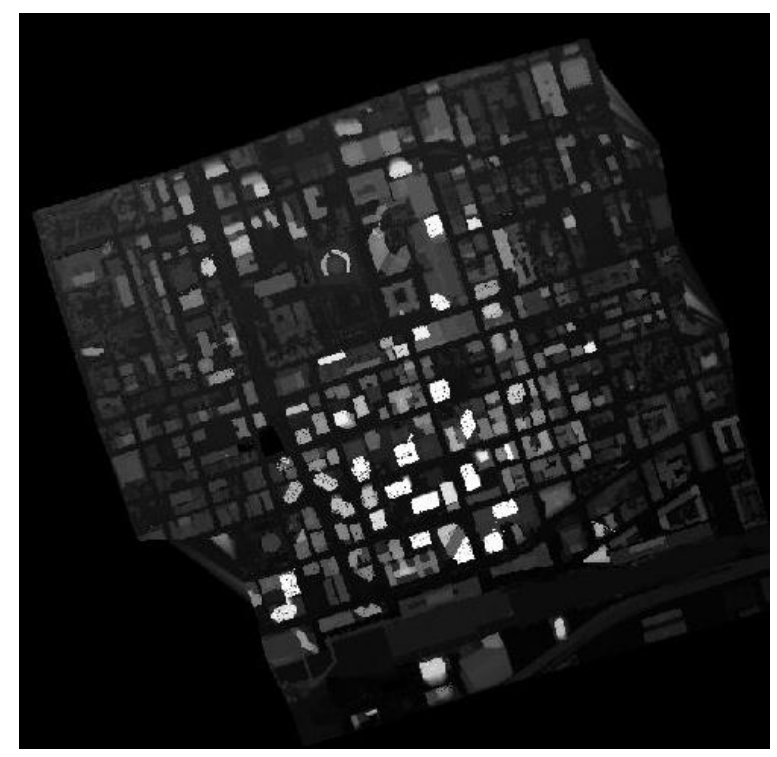

(b)

Figure 10. (a) indicates the used parameters and (b) depicts produced DSM from Lastool 


\section{Digital Elevation Model (DEM)}

Digital Elevation Model (DEM) was produced from the merged file of the las point cloud using lastool software. The last pulse data from LiDAR gives data from the surface that was the last hit by the laser pulse. However, for returns from the ground and landscape features (such as vegetation), it is the last pulse that would give the elevation of the surface last hit by the pulse, or nearest to the ground (Figure 11). The following parameters were used in Lastool software for producing DEM:

Grid size 3

Item elevation

Output .img

By classification of return: last only

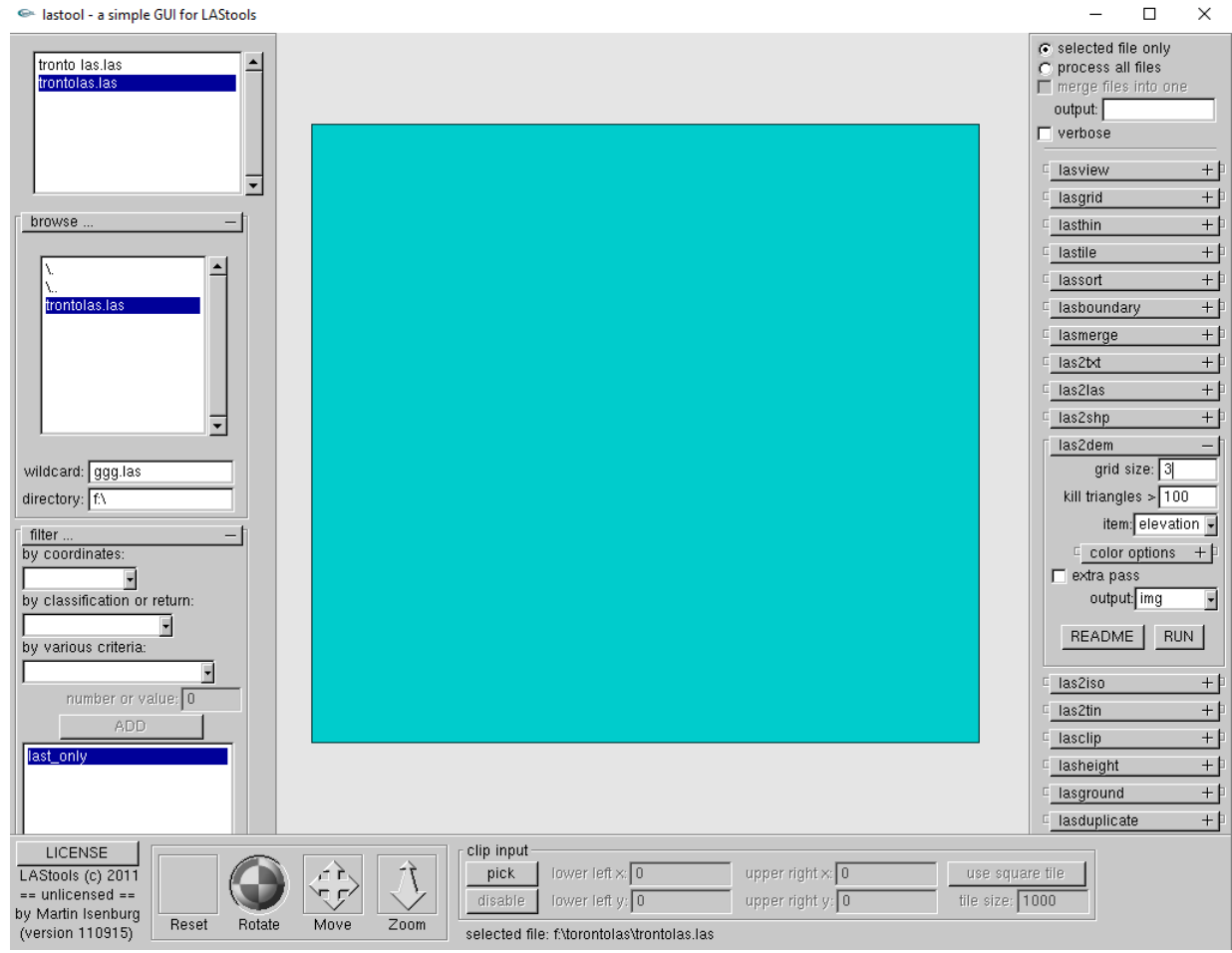

(a)

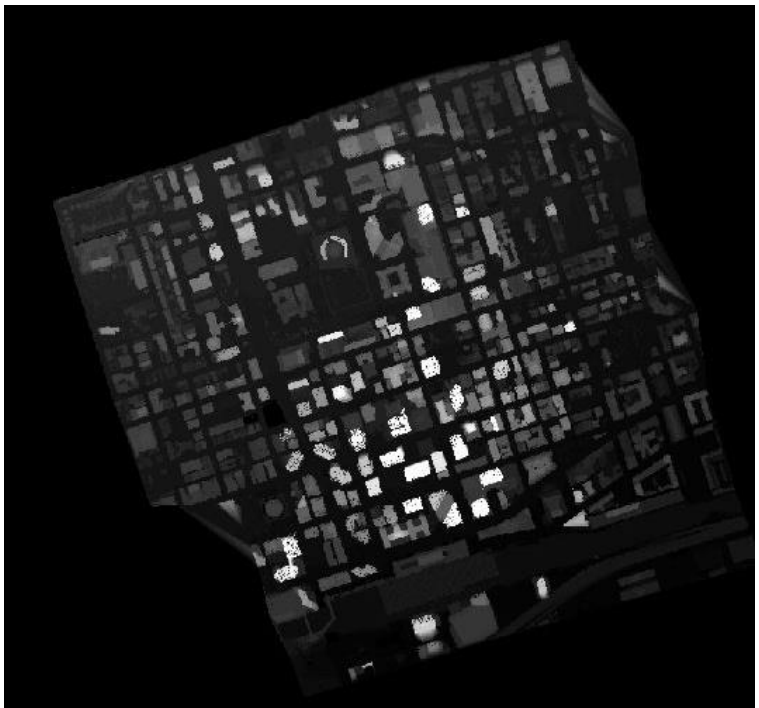

(b)

Figure 11. (a) depicts the used parameters for DEM extraction in Lastools and (b) illustrates DEM from Lastool 


\subsubsection{Calculation of normalized digital surface model (nDSM)}

After the computation of both DTM and DSM, nDSM has been calculated by subtraction of DTM from DSM (DSM-DTM). ENVI band math was used for this purpose. Figure 12 depicts difference between DSM and DTM.

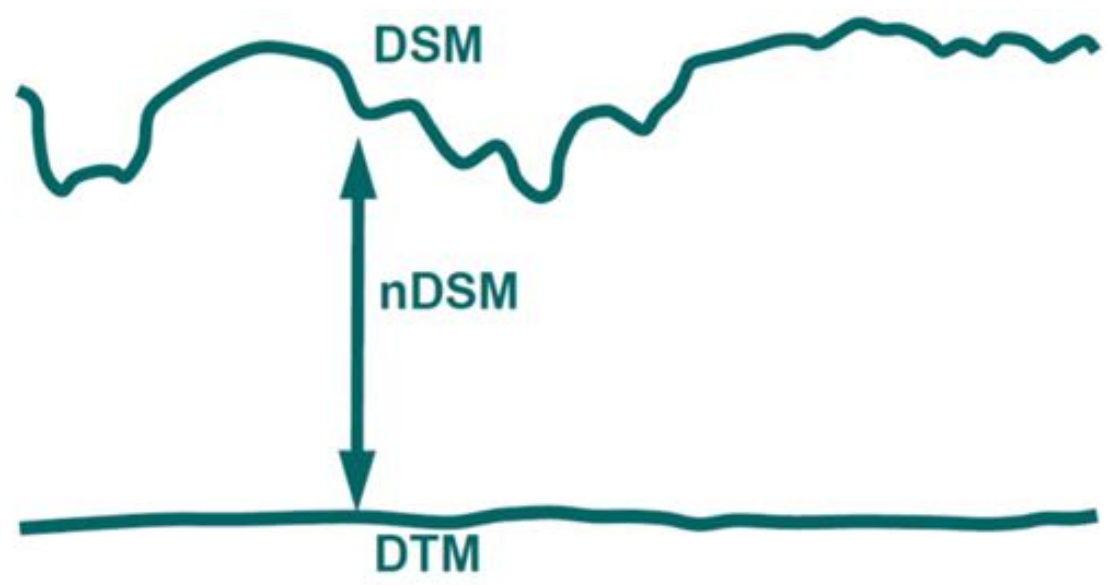

Figure 12. Difference between DSM and DTM

\subsubsection{Texture extraction}

Texture analysis offers interesting possibilities to characterize the structural heterogeneity of classes. In the statistical approach, the stochastic properties of the spatial distribution of the grey level (GL) in the image are characterized. Amongst all popular algorithms, Grey Level Co-occurrence Matrix (GLCM) is the widely adopted one (Shaker, Yan, \& El-Ashmawy, 2012; Alhaddad, Roca, \& Burns, 2009). The co-occurrence matrix is a method which surveys image pixel and describes the distribution of gray. It can generate some texture measures (Zou \& Li, 2009). First-order texture measures on GLCM consists of Standard Deviation, Range, Minimum, Maximum, and Mean. The second order of texture measures includes Angular Second Moment, Contrast, Correlation, Dissimilarity, Entropy, Information Measures of Correlation, Inverse Difference Moment, and Sum of Squares Variance. The third-order texture measures such as skewness. The fourth-order texture measures such as kurtosis.

Texture information was extracted from the LIDAR DSM band using ENVI 5.1 software, forming new bands based on two texture measures. The statistical measures used in this study are mean and entropy.

$\mathrm{N}-1 \mathrm{~N}-1$

Mean $=\sum_{i=0} \sum_{j=0}^{i P_{i, j}} \quad$ Equation 1

$\mathrm{N}-1 \mathrm{~N}-1$

Entropy $=$ Ent $=\sum_{i=0} \sum_{j=0} P_{i, j}\left(-\ln P_{i, j}\right) \quad$ Equation 2

Texture information was extracted from the LIDAR DSM band using ENVI 5.1 software, forming new bands based on two texture measures. The statistical measures used in this study are mean and entropy. A window size of $5 * 5$ was adopted (Figure 13 ). 


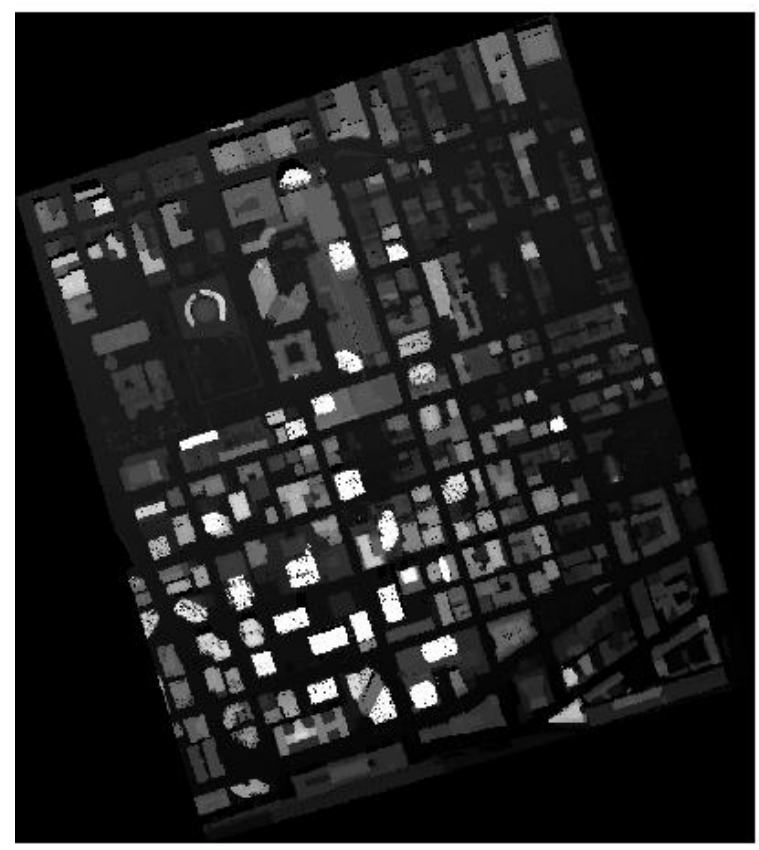

(a)

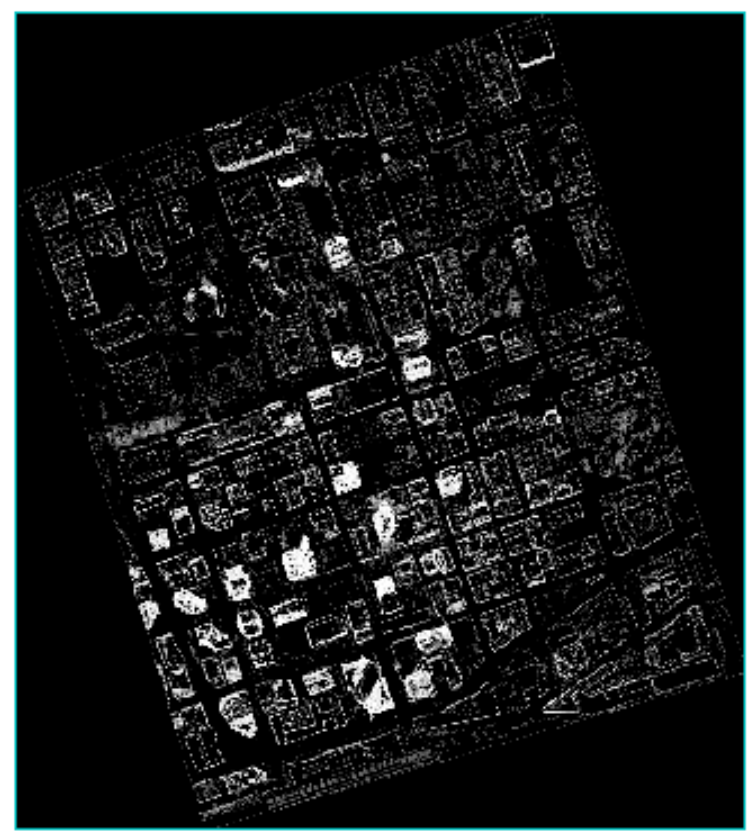

(b)

Figure 13. (a) Mean texture of all strips and (b) Entropy texture of all strips

\subsubsection{Classification process}

The framework consists of three major parts:(1) data combination; (2) classification; and (3) evaluation.

1. Maximum likelihood classifier

Maximum likelihood (ML) classifier is the most commonly used supervised method in remote sensing. $\mathrm{ML}$ classifier is one of the statistical classifiers that depend on the multivariate normal distribution of the data in each class (Kavzoglu \& Colkesen, 2009). By computing the mean spectral vector and covariance matrix for each spectral class from training samples, a decision function is generated to calculate the probability of 
a pixel belonging to this specific class according to Bayesian theorem. By comparing the probabilities of a pixel belonging to all classes, the pixel is then categorized into the class with the maximum probability (J. Zhang, Zhang, \& Yao, 2009).

\section{Minimum Distance (MD)}

The minimum distance classification is performed by placing a pixel in the class of the nearest mean. It uses the mean vectors of each region of interest (ROI) and calculates the Euclidean distance from each unknown pixel to the mean vector for each class. All pixels are classified to the closest ROI class unless the user specifies standard deviation or distance thresholds, in which case some pixels may be unclassified if they do not meet the selected criteria. This method calculates the center for each group of pixels and measures the distance from the center of each group to the pixel being considered. The pixel is classified into the group with the nearest center. The center of the group then is recalculated each time a pixel is added or taken away. The feature vector is computed for these samples again and a distance Euclidean and Mahalanobis classifiers are used to classify the unknown samples (Mandal \& Prabaharan, 2006).

\section{Artificial Neural Network (ANN)}

The MLP-BP model with three layers (input, hidden, and output layer) was employed. The number of input neurons is equal to a number of input features, the number of neurons in the output layer is the number of land cover classes to be classified. The number of neurons in the hidden layer was determined by the sequential testing and validation process using the training data (Kavzoglu \& Colkesen, 2009). The sigmoid function was used as the transfer function. The other parameters were set as follows: maximum number of iteration: 1000; learning rate: 0.01-0.1; training momentum: 0.9

Maximum likelihood, Minumum distance, and Neural network classifiers have been used for feature detection, firstly, feature detection from the classification of color-true ortho aerial camera image only. The second approach is feature detection from the classification of combined height information from LIDAR data (DSM )image and two texture measures (mean and entropy). The third approach is feature detection based on combined intensity image classification and two texture measures (mean and entropy). The fourth approach is the classification of combined intensity image and nDSM and means texture measure. The fifth approach is the classification of combined intensity image and nDSM and entropy texture measure

Three land cover classes have been defined (buildings, agricultural lands, roads), plus a class for shadows. Shadows are not a problem for low-resolution satellite images, contrary to high-resolution ones such as digital aerial camera images, where shadows play a relevant role.

Signatures have been collected and evaluated from the resulted in three cases. Accuracy assessment of classifications was carried out using the overall accuracy and kappa coefficient. Seventy randomly selected points were used for this purpose.

Table 3. Overall classification accuracy and Kappa coefficient for the five approaches using neural network classification

\begin{tabular}{lcc}
\hline \multicolumn{1}{c}{ Approach } & overall Accuracy \% & Kappa coefficient \\
\hline aerial color image alone & 78.15 & 0.73 \\
combined height information from LIDAR data (DSM )image & 93.49 & 0.89 \\
and two texture measures (mean and entropy) & & \\
intensity image +mean+ entropy & 94.19 & 0.91 \\
combined intensity (pan) +nDSM+mean & 95.60 & 0.92 \\
\hline combined intensity (pan) +nDSM+ entropy & 96.24 & 0.94 \\
\hline
\end{tabular}




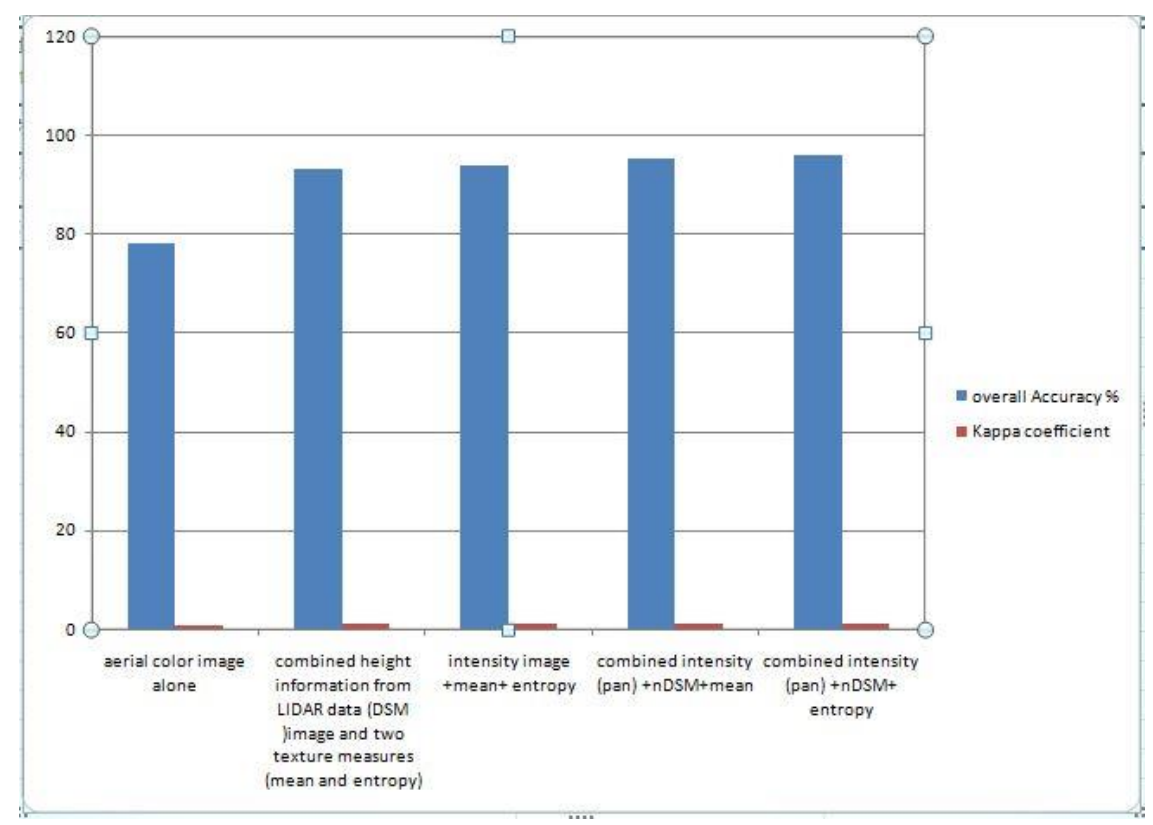

Figure 14. Overall classification accuracy and Kappa coefficient for the five approaches using neural network classification

Table 4. Overall classification accuracy and Kappa coefficient for the five approaches using Minimum distance classification

\begin{tabular}{lrr}
\multicolumn{1}{c}{ Approach } & overall Accuracy \% & Kappa coefficient \\
\hline $\begin{array}{l}\text { aerial color image alone } \\
\text { combined height information from LIDAR data (DSM) image }\end{array}$ & 75.35 & 0.76 \\
and two texture measures (mean and entropy) & 87.76 & 0.81 \\
intensity image +mean+ entropy & & \\
combined intensity (pan) +nDSM+mean & 88.91 & 0.87 \\
\hline \hline combined intensity (pan) +nDSM+ entropy & 92.46 & 0.89 \\
\hline
\end{tabular}

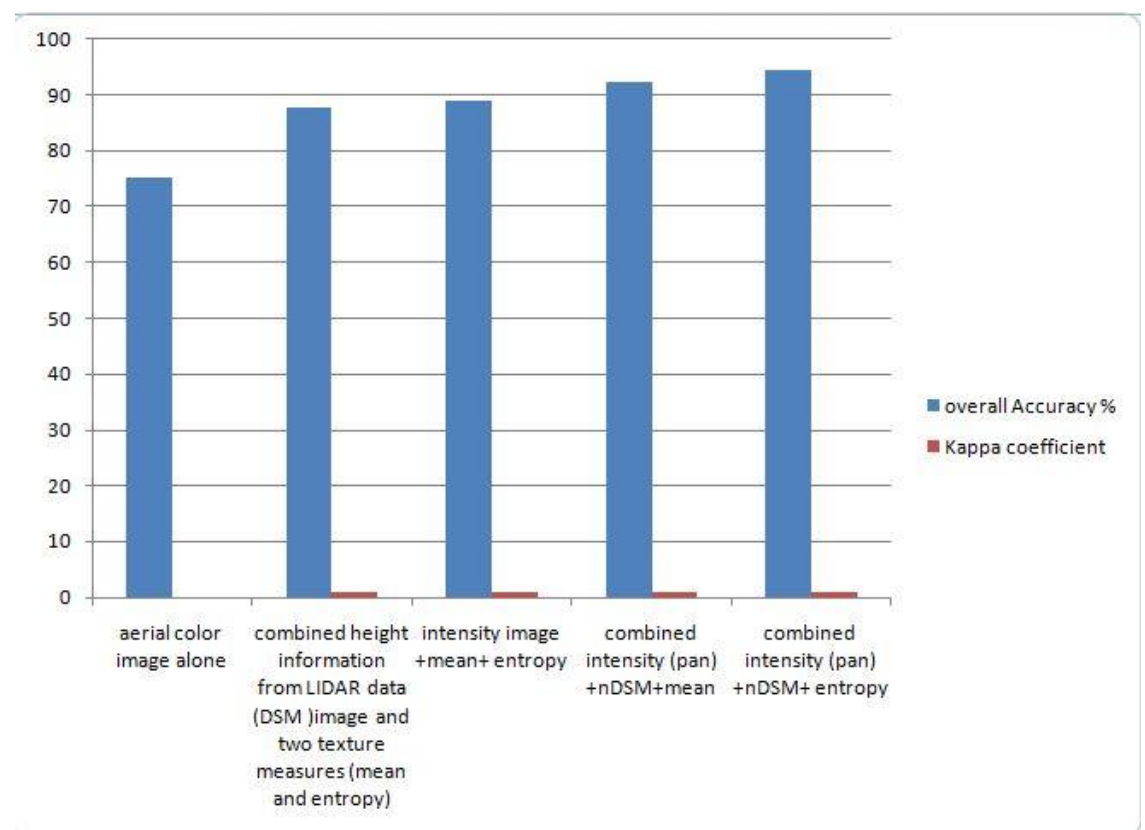

Figure 15. Overall classification accuracy and Kappa coefficient for the five approaches using Minimum distance classification 
Table 5. Overall classification accuracy and Kappa coefficient for the five approaches using maximum likelihood classification

\begin{tabular}{crr|}
\hline Approach & overall Accuracy \% & Kappa coefficient \\
\hline aerial color image alone & 80.65 & 0.75 \\
\hline $\begin{array}{c}\text { combined height information from LIDAR data (DSM )image } \\
\text { and two texture measures (mean and entropy) }\end{array}$ & 95.89 & 0.89 \\
\hline $\begin{array}{c}\text { intensity image +mean+ entropy } \\
\text { combined intensity (pan) +nDSM+mean }\end{array}$ & 96.05 & 0.91 \\
\hline combined intensity (pan) +nDSM+ entropy & 97.4 & 0.94 \\
\hline
\end{tabular}

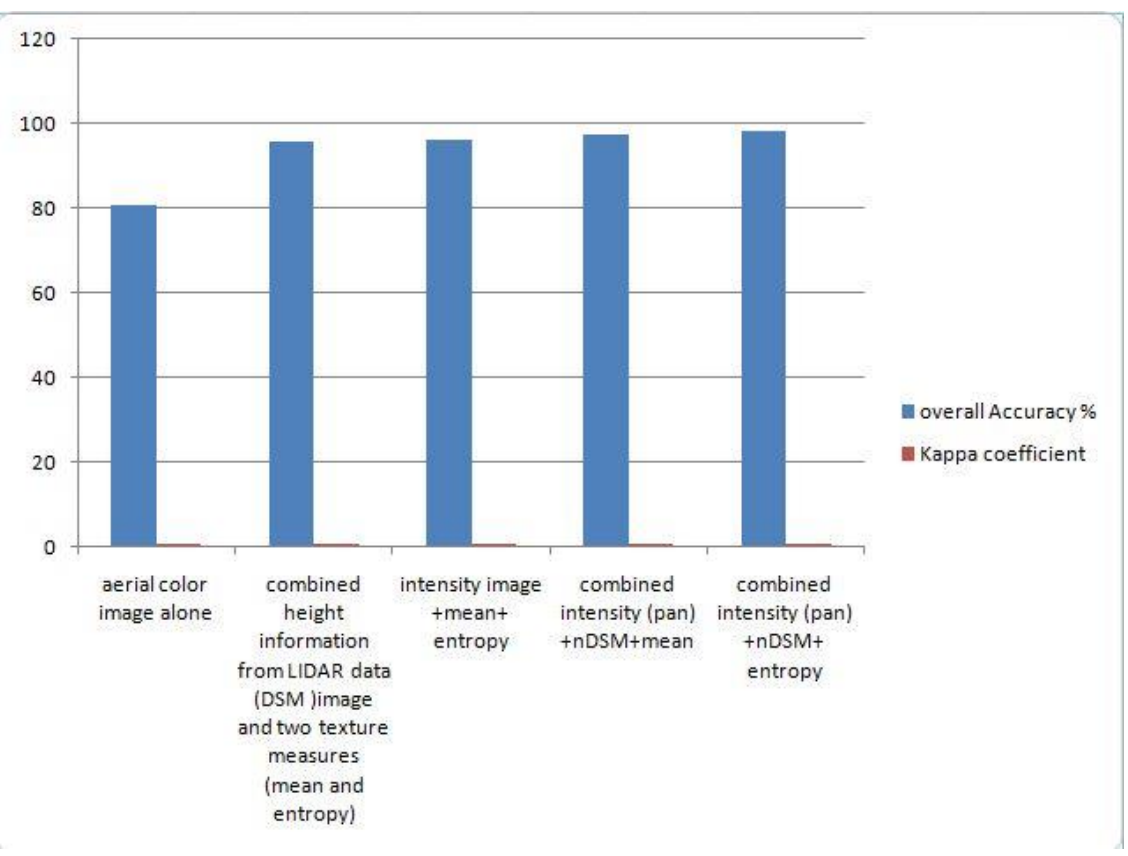

Figure 16. Overall classification accuracy and Kappa coefficient for the five approaches using maximum likelihood classification

\section{RESULTS AND DISCUSSION}

Firstly, image orientation AT has been performed. The resulted RMS of triangulation was $0.192 \mathrm{~m}$. Then the automatic digital surface model DSM generation has been produced from a digital aerial camera. It was found that LIDAR DSM is more accurate than the digital aerial camera DSM.

Thirdly true digital orthophoto has been generated from a digital aerial camera also orthoimage will be generated using LIDAR digital elevation model (DSM). Leica Photogrammetric Suite (LPS) module of Erdsa Imagine 2014 software was utilized for processing. Then the resulted orthoimages from both techniques were mosaicked. The results show that the automatic digital surface model DSM produced from the digital aerial camera method has very high dense photogrammetric 3D point clouds compared to the LIDAR 3D point clouds. It was found that the true orthoimage produced from the second approach is better than the true orthoimage produced from the first approach.

The five approaches were tested for classification of the best-orthorectified image mosaic using subpixel based (neural network) and pixel-based ( minimum distance and maximum likelihood). Multicues were extracted such as texture(entropy-mean),Digital elevation model, Digital surface model ,normalized digital surface model (nDSM) and intensity image. The contributions of the individual cues used in the classification have been evaluated. 
It was found that the best cue integration is intensity (pan) +nDSM+ entropy followed by intensity (pan) $+n D S M+m e a n$ then intensity image +mean+ entropy after that DSM )image and two texture measures (mean and entropy) followed by the color image. The integration with height data increases the accuracy. Also, it was found that the integration with entropy texture increases the accuracy.

Resulted in fifteen classification cases, it was found that the maximumlihood classifier is the best followed by minimum distance then neural network classifier. We attribute this to the fine resolution of the digital camera image. Subpixel classifier (neural network) is not suitable for classifying aerial digital camera images.

LiDAR and photogrammetry are complementary to each other, and thus the integration of both technologies is important in a number of remote sensing applications such as building extraction, image classification, 3D city modeling, and so on. The integration of LiDAR and photogrammetry is expected to produce more accurate and higher-quality products.

Leica Photogrammetric Suite (LPS) -Erdas imagine 2014 software has been used for producing true digital orthoimages from digital aerial camera images using DSM from LIDAR data and DSM produced from the digital aerial camera. True orthomosaic was then generated for both sets.

Several recent studies have demonstrated the use of Lidar for high-quality digital surface models (Brédif et al., 2013; Huo et al., 2018; Mahadi et al., 2018; Margolis et al., 2017; Shirowzhan \& Trinder, 2017). The increasing quality of digital airborne cameras and improvements in matching algorithms allow for an automatic image-based acquisition as a suitable alternative (Haala \& Rothermel, 2012). This study shows that the digital surface model from Lidar is more accurate than the digital aerial camera. However, the combination of Lidar and photogrammetry produces more accurate and quality results.

\section{CONCLUSION}

This research succeeded in making the digital elevation model from a digital aerial camera and LIDAR data for urban feature extraction. The results show that the automatic digital surface model DSM that has been produced from the digital aerial camera method has very high dense photogrammetric 3D point clouds compared to the LIDAR 3D point clouds. It was found that the true orthoimage produced from the second approach is better than the true orthoimage produced from the first approach.

It was found that the maximumlihood classifier is the best followed by minimum distance then neural network classifier. It is recommended to evaluate building extraction from las point clouds produced from the digital aerial camera and LIDAR data. It is also recommended to implement a filtering software to get DEM from DSM.

\section{ACKNOWLEDGMENTS}

The authors would like to acknowledge the provision of the Downtown Toronto data set by Optech Inc., First Base Solutions Inc., York University, and ISPRS WG III/4. The editing and comments of the reviewers is gratefully appreciated.

\section{REFERENCES}

Alhaddad, B., Roca, J., \& Burns, M. (2009). Monitoring urban sprawl from historical aerial photographs and satellite imagery using texture analysis and mathematical morphology approaches. A: European Congress of the Regional Science Association International." Territorial Cohesion of Europe \& Integrative Planning: 49th European Congress of the Regional Science Association International, 25-29.

Brédif, M., Tournaire, O., Vallet, B., \& Champion, N. (2013). Extracting polygonal building footprints from digital surface models: A fully-automatic global optimization framework. ISPRS Journal of Photogrammetry and Remote Sensing, 77, 57-65. [Crossref]

Demir, N., Poli, D., \& Baltsavias, E. (2008). Extraction of buildings and trees using images and LiDAR data. International Archives of the Photogrammetry, Remote Sensing and Spatial Information Sciences, 
37(B4), 313-318.

Foody, G. M., \& Mathur, A. (2004). Toward intelligent training of supervised image classifications: directing training data acquisition for SVM classification. Remote Sensing of Environment, 93(1-2), 107-117. [Crossref]

Haala, N., \& Rothermel, M. (2012). Dense multi-stereo matching for high quality digital elevation models. Photogrammetrie-Fernerkundung-Geoinformation, 2012(4), 331-343. [Crossref]

Honkavaara, E., Peltoniemi, J., Ahokas, E., Kuittinen, R., Hyyppa, J., Jaakkola, J., ... Suomalainen, J. (2008). A permanent test field for digital photogrammetric systems. Photogrammetric Engineering and Remote Sensing, 74(1). [Crossref]

Huo, L. Z., Silva, C. A., Klauberg, C., Mohan, M., Zhao, L. J., Tang, P., \& Hudak, A. T. (2018). Supervised spatial classification of multispectral LiDAR data in urban areas. PLOS ONE, 13(10), 1-17. [Crossref]

Jochem, A., Höfle, B., Rutzinger, M., \& Pfeifer, N. (2009). Automatic roof plane detection and analysis in airborne lidar point clouds for solar potential assessment. Sensors, 9(7), 5241-5262. [Crossref]

Kavzoglu, T., \& Colkesen, I. (2009). A kernel functions analysis for support vector machines for land cover classification. International Journal of Applied Earth Observation and Geoinformation, 11(5), 352-359. [Crossref]

Kunapo, J. (2005). Spatial data integration for classification of 3D point clouds from digital photogrammetry. Applied GIS, 1(3), 21-26. [Crossref]

Mahadi, A. T., Siregar, V. P., \& Nursugi. (2018). Mapping of mangrove coverage and canopy height using LiDAR data at Sangkulirang District, East Kutai, East Borneo. IOP Conference Series: Earth and Environmental Science, 176(1). [Crossref]

Mandal, S., \& Prabaharan, N. (2006). Ocean wave forecasting using recurrent neural networks. Ocean Engineering, 33(10), 1401-1410. [Crossref]

Margolis, R., Gagnon, P., Melius, J., Phillips, C., \& Elmore, R. (2017). Using GIS-based methods and lidar data to estimate rooftop solar technical potential in US cities. Environmental Research Letters, 12(7). [Crossref]

Rinaudo, F., Chiabrando, F., Nex, F., \& Piatti, D. (2010). New instruments and technologies for Cultural Heritage survey: full integration between point clouds and digital photogrammetry. EuroMediterranean Conference, 56-70. [Crossref]

Sebari, I., Lahmami, H., \& Ettarid, M. (2011). Assessment and comparison of the quality of digital orthoimages generated from digital aerial images and from scanned analogue aerial images. FIG Working Week.

Shaker, A., Yan, W. Y., \& El-Ashmawy, N. (2012). Panchromatic satellite image classification for flood hazard assessment. Journal of Applied Research and Technology, 10(6), 902-911. [Crossref]

Shirowzhan, S., \& Trinder, J. (2017). Building Classification from Lidar Data for Spatio-temporal Assessment of 3D Urban Developments. Procedia Engineering, 180, 1453-1461. [Crossref]

Valbuena, R., Mauro, F., Arjonilla, F. J., \& Manzanera, J. A. (2011). Comparing airborne laser scanning-imagery fusion methods based on geometric accuracy in forested areas. Remote Sensing of Environment, 115(8), 1942-1954. [Crossref]

Wyatt, B. K. (2000). Remote sensing of land cover and land cover change. In Observing Land from Space: Science, Customers and Technology (pp. 127-136). Springer. [Crossref]

Yunfei, B., Guoping, L., Chunxiang, C., Xiaowen, L., Hao, Z., Qisheng, H., ... Chaoyi, C. (2008). Classification of LIDAR point cloud and generation of DTM from LIDAR height and intensity data in forested area. The International Archives of the Photogrammetry, Remote Sensing and Spatial Information Sciences, 37(7), 313-318.

Zhang, J., Zhang, J., \& Yao, N. (2009). Uncertainty characterization in remotely sensed land cover information. Geo-Spatial Information Science, 12(3), 165-171. [Crossref]

Zhang, L., Kocaman, S., Kornus, W., \& Baltsavias, E. (2006). Calibration and validation of digital airborne cameras. International Archives of the Photogrammetry, Remote Sensing and Spatial Information Sciences, 36(1).

Zou, X., \& Li, D. (2009). Application of image texture analysis to improve land cover classification. WSEAS Transactions on Computers, 8(3), 449-458. 